\title{
Inequalities in utilisation of general practitioner and specialist services in 9 European countries
}

\author{
Irina Stirbu ${ }^{1 *}$, Anton E Kunst ${ }^{1,2}$, Andreas Mielck $^{3}$ and Johan P Mackenbach ${ }^{1}$
}

\begin{abstract}
Background: The aim of this study is to describe the magnitude of educational inequalities in utilisation of general practitioner (GP) and specialist services in 9 European countries. In addition to West European countries, we have included 3 Eastern European countries: Hungary, Estonia and Latvia. To cover the gap in knowledge we pay a special attention to the magnitude of inequalities among patients with chronic conditions.

Methods: Data on the use of GP and specialist services were derived from national health surveys of Belgium, Estonia, France, Germany, Hungary, Ireland, Latvia, the Netherlands and Norway. For each country and education level we calculated the absolute prevalence and relative inequalities in utilisation of GP and specialist services. In order to account for the need for care, the results were adjusted by the measure of self-assessed health.

Results: People with lower education used GP services equally often in most countries (except Belgium and Germany) compared with those with a higher level of education. At the same time people with a higher education used specialist care services significantly more often in all countries, except in the Netherlands. The general pattern of educational inequalities in utilisation of specialist care was similar for both men and women. Inequalities in utilisation of specialist care were equally large in Eastern European and in Western European countries, except for Latvia where the inequalities were somewhat larger. Similarly, large inequalities were found in the utilisation of specialist care among patients with chronic diseases, diabetes, and hypertension.
\end{abstract}

Conclusions: We found large inequalities in the utilisation of specialist care. These inequalities were not compensated by utilisation of GP services. Of particular concern is the presence of inequalities among patients with a high need for specialist care, such as those with chronic diseases.

Keywords: health utilization, specialist services, socio-economic inequalities, Europe

\section{Background}

Access to health care for all in need is a basic social right. At first sight, all European countries have universal insurance coverage and, thus, it is often assumed that these countries also enjoy universal and equitable access to health care services. However, a number of studies indicate that that is not the case [1-7]. Although utilisation of general practitioner (GP) services is distributed fairly equally, independent of income, less well-off people appear to be much less likely to see a specialist than their wealthier counterparts, despite their higher need for such care. This phenomenon is universal in Europe, but seems

\footnotetext{
* Correspondence: i.stirbu@nivel.nl

${ }^{1}$ Department of Public Health, Erasmus Medical Centre Rotterdam, Erasmus University, The Netherlands

Full list of author information is available at the end of the article
}

to be stronger in countries where either private insurance or private practice options are offered [1].

Although a number of international studies have documented inequalities in utilisation of health care services in European countries, this information remains incomplete. Previously only income inequalities in utilisation were studied internationally, thus information is lacking regarding educational inequalities in the use of health services. A theoretical argument in favour of also using education is its growing importance in relation to the relative position of the individual in the distribution of other important assets such as paid labour, occupational status and income level. Additionally, previous studies largely focused on West European countries, missing the growing "new" European populations for which the magnitude of socioeconomic inequalities has hardly been
C Biomed Central

다 2011 Stirbu et al; licensee BioMed Central Ltd. This is an Open Access article distributed under the terms of the Creative Commons Attribution License (http://creativecommons.org/licenses/by/2.0), which permits unrestricted use, distribution, and reproduction in any medium, provided the original work is properly cited. 
studied [8]. Inequalities in Eastern European countries might be larger than in Western European countries due to recent disruptions in social and health care systems in those countries [8-10]. Finally, all studies on inequalities in utilisation were mainly based on the general population, thus not taking into account people with special needs, such as those with chronic diseases. Large inequalities in the utilisation of health care services in this vulnerable group might indicate specific potential shortcomings within the health care system and support hypotheses about the role of access in explaining differential outcomes of care among people with different socioeconomic status.

The aim of the present study is to describe the magnitude of educational inequalities in utilisation of GP and specialist services in 9 European countries. In addition to West European countries, we have included 3 Eastern European countries: Hungary, Estonia and Latvia. Special attention is also paid to the magnitude of inequalities among patients with chronic conditions.

\section{Methods}

\section{Data}

Data on utilisation of GP and specialist services were derived from micro-level data of national health surveys in 9 European countries (Norway, Ireland, Netherlands, Belgium, Germany, France, Hungary, Estonia, and Latvia). Most surveys were conducted in or after the year 2000, except for the German survey which was conducted in 1998 (Table 1). Sample sizes were above 7000 persons for all surveys, except those from Estonia and Norway. Nonresponse percentages ranged from about 18\% in Ireland up to $42 \%$ in the Netherlands and Belgium, while percentages in most other countries were around 30\%. Data from 104,503 respondents were included in the analyses.

In all surveys, utilisation of GP and specialist services was self-reported. All participants were asked how many times they visited a GP or a specialist in a specified period of time. In all countries the recall period for utilisation of
GP and specialist services was 12 months, except for the Netherlands and Belgium where the recall period was only 2 months.

In order to take the need for care into account we have included the measure of self-assessed health. Self-assessed health was rated according to 5 answer categories from the healthiest to the least healthy. The exact answer categories ranged in most countries from "very good" to "very bad", although there were some variations between countries. Additionally, the utilisation of services was investigated among people with chronic diseases. In all surveys the presence of chronic diseases was self-reported, except for Ireland that had no data on chronic diseases. Because each survey varied depending on the type and number of chronic diseases included, we selected only those chronic disease that were present in at least 6 of the 9 surveys: angina pectoris, arthritis, asthma, bronchitis, cancer, diabetes, hypertension, myocardial infarction, stroke, and ulcers. A patient was considered to be having a chronic disease if $s /$ he reported having at least one from the above mentioned chronic conditions. Information on diabetes and hypertension was included in all surveys, and prevalence rates were high in all countries; this allowed us to use these diseases for a more in-depth analysis.

Socioeconomic position was measured using the level of education, which represents the highest level of completed education of the respondent. The level of education was initially classified according to national categories, which were subsequently reclassified into three levels of the International System of Classification of Educations (ISCED): primary or no education and lower secondary education; higher secondary education; tertiary education.

\section{Analysis}

First, we assessed educational inequalities in utilisation of GP and specialist services using prevalence rates of having made at least one visit to a GP or specialist. Prevalence rates were calculated for each type of service by education group and participating country. The prevalence rates

Table 1 Countries included in the analysis and sources of data

\begin{tabular}{|c|c|c|c|c|}
\hline Country & Survey name & Year(s) & Non-response (\%) & Final sample \\
\hline Norway & Norwegian Survey of Living Conditions & 2002 & 29.6 & 6820 \\
\hline Ireland & Living in Ireland Panel Survey & 1995, 2002 & $18.0 / 22.0^{*}$ & 15051 \\
\hline Netherlands & General social survey (POLS) & $2003-2004$ & $41.7-38.7$ & 15803 \\
\hline Belgium & Health Interview Survey & 1997, 2001 & $41.5 / 38.6^{*}$ & 18481 \\
\hline Germany & German National Health Examination and Interview Survey & 1998 & 38.6 & 7124 \\
\hline France & Health, Health Care and Insurance Survey (IRDES) & 2004 & $30.0^{*}$ & 17828 \\
\hline Hungary & National Health Interview Survey Hungary & 2000,2003 & $21.0-28.0$ & 10532 \\
\hline Estonia & Health Behavior among Estonian Adult Population & 2002, 2004 & $33.0 / 38.0^{*}$ & 4376 \\
\hline Latvia & Finbalt Health Monitor & 1998; 2000; 2002; 2004 & $20.0-40.0$ & 8488 \\
\hline Europe & & & & 104503 \\
\hline
\end{tabular}

* Percentage non-response households 
were standardized by 5 -year age groups and gender to the total survey population, as a representative sample for the standard European population. We use prevalence rates to judge about the absolute differences of GP or specialist services use between different educational groups.

Second, we estimated relative inequalities in utilisation of GP and specialist services among higher and lower educational groups of the general population using the relative index of inequality (RII). The RII is a regression-based index used to measure socioeconomic inequalities in health in a comparable way in different countries $[11,12]$. The RII quantifies the relative position of each educational group within the hierarchy of all educational groups. This rank measure is related to health indicators by means of log-binomial regression. The RII results in a ratio that can be described as the prevalence ratio of preventive services utilisation at the very bottom of the educational hierarchy compared to the very top of the hierarchy.

Third, we estimated relative inequalities by education in utilisation of GP and specialist services among persons with chronic diseases, hypertension and diabetes.

All calculations were done using log-binomial regression analysis in SAS statistical package (version 8.02). We included categorical variables in the regression models, representing 5-year age groups and gender, to control for demographic confounders. To take the need for care into account, we adjusted our results by the ranked measure of self-assessed health, which quantifies the relative position of each group of people in one answer category in the hierarchy of all answer categories. Ranked measure of selfassessed health was calculated on the basis of the cumulative relative frequencies of the valid cases and allows for better comparison between countries.

\section{Results}

The study populations in the different European countries did not differ greatly regarding age and gender distribution (Table 2), except for the Baltic countries where there were slightly more younger female respondents. In contrast, there was a considerable difference in educational distribution between the countries, with Norway and the Netherlands having fewer people with lower education, and Germany, Hungary and Ireland having fewer people with higher education. In most countries, the percentage of people reporting visiting a GP ranged from $67 \%$ to $80 \%$; it was substantially lower in Latvia, the Netherlands and Belgium (range 35\% to 46\%). In the latter 2 countries the lower rates of GP visits is probably related to the shorter recall period ( 2 and 3 months, respectively, versus 12 months in all other countries). The highest report for visiting a specialist was in Germany (75\%) and the lowest was in Norway (17\%).

Only in Belgium and Germany were lower educated people significantly more likely to report a visit to a GP (RII is 1.29 and 1.20, respectively; Table 3). After adjustment for self-assessed health the RII slightly decreased in all countries. Although utilisation of GP care was fairly equally distributed between educational groups, there was a general tendency of lower use by the lower educated (RIIs just below 1 in all countries except Belgium and Germany). In Belgium and Germany significantly higher utilisation of GP services by lower educated groups remained, although weakened. On the other hand, after adjustment for self-assessed health, in Hungary higher educated people used GP services significantly more often compared to the lower educated group $(\mathrm{RII}=0.87$ CI: 0.80-0.95).

The prevalence of specialist services use was more diverse compared with GP services, with higher utilisation in Germany, France, Hungary and Estonia (above $40 \%$ for both higher and lower educated groups; Table 3 ). Higher educated people reported using specialist services significantly more often than lower educated people in almost all countries, except for the Netherlands (RII = 1.05) where utilisation was equal for higher and lower educated groups. After adjustment for self-assessed health, people with higher education reported using specialist services significantly more often in all countries,

Table 2 Background information on the study populations

\begin{tabular}{|c|c|c|c|c|c|c|c|}
\hline Country & $\begin{array}{l}\text { Age above } \\
50 \text { yrs (\%) }\end{array}$ & $\begin{array}{l}\text { Gender } \\
\text { distribution (\% } \\
\text { men) }\end{array}$ & $\begin{array}{l}\% \text { Lower secondary } \\
\text { education and below }\end{array}$ & $\begin{array}{l}\text { \% Upper } \\
\text { secondary } \\
\text { education }\end{array}$ & $\begin{array}{l}\text { \% Tertiary } \\
\text { education }\end{array}$ & $\begin{array}{l}\text { People reporting } \\
\text { visiting a GP (\%) }\end{array}$ & $\begin{array}{l}\text { People reporting } \\
\text { visiting a specialist } \\
(\%)\end{array}$ \\
\hline Norway & 39.8 & 50.0 & 17.5 & 56.6 & 25.9 & 74.8 & 17.0 \\
\hline Ireland & 37.5 & 49.5 & 55.9 & 29.8 & 14.3 & 72.8 & 24.8 \\
\hline Netherlands & 42.7 & 48.5 & 39.3 & 37.7 & 22.9 & 35.6 & 18.0 \\
\hline Belgium & 42.0 & 48.5 & 41.0 & 30.0 & 29.0 & 46.8 & 22.9 \\
\hline Germany & 42.7 & 48.4 & 43.0 & 43.1 & 13.9 & 67.9 & 74.7 \\
\hline France & 39.5 & 49.1 & 53.7 & 18.9 & 27.4 & 80.5 & 56.9 \\
\hline Hungary & 42.8 & 44.6 & 57.6 & 29.0 & 13.4 & 74.1 & 51.7 \\
\hline Estonia & 30.1 & 42.3 & 47.9 & 34.5 & 17.6 & 67.3 & 44.6 \\
\hline Latvia & 28.9 & 43.5 & 44.3 & 34.6 & 21.1 & 44.5 & 29.1 \\
\hline Europe & 39.4 & 47.8 & 46.0 & 32.3 & 21.7 & 59.2 & 35.7 \\
\hline
\end{tabular}


Table 3 Prevalence rate (PR) and Relative index of inequality (RII) in utilisation of GP and specialist services

\begin{tabular}{|c|c|c|c|c|c|c|c|}
\hline Country & $\begin{array}{l}\text { PR }{ }^{a} \text { Lower secondary } \\
\text { education and below }\end{array}$ & $\begin{array}{l}\text { PR Upper } \\
\text { secondary } \\
\text { education }\end{array}$ & $\begin{array}{l}\text { PR Tertiary } \\
\text { education }\end{array}$ & $\begin{array}{l}\text { RII }(95 \% \mathrm{Cl})^{\mathrm{b}} \text {, } \\
\text { Men \& } \\
\text { women, } \\
\text { Adjusted for } \\
\text { age \& gender }\end{array}$ & $\begin{array}{c}\text { RII }(95 \% \mathrm{Cl}) \\
\text { Men \& women } \\
\text { Adjusted for age, } \\
\text { gender \& } \mathrm{SAH}^{\mathrm{c}}\end{array}$ & $\begin{array}{l}\text { RII }(95 \% \mathrm{Cl}) \text {, } \\
\text { Men } \\
\text { Adjusted for } \\
\text { age \& } \mathrm{SAH}^{\mathrm{c}}\end{array}$ & $\begin{array}{l}\text { RII }(95 \% \mathrm{Cl}) \text {, } \\
\text { Women } \\
\text { Adjusted for } \\
\text { age \& } \mathrm{SAH}^{\mathrm{c}}\end{array}$ \\
\hline \multicolumn{8}{|c|}{ Utilization of GP services } \\
\hline Norway & 75.1 & 75.8 & 73.3 & $1.07(0.96-1.20)$ & $0.98(0.87-1.10)$ & $1.06(0.90-1.26)$ & $0.92(0.78-1.08)$ \\
\hline Ireland & 74.7 & 69.7 & 71.3 & $1.07(0.95-1.20)$ & $0.97(0.87-1.09)$ & $0.87(0.74-1.04)$ & $1.07(0.92-1.26)$ \\
\hline Netherlands & 35.6 & 35.8 & 33.6 & $1.08(0.98-1.20)$ & $0.93(0.84-1.04)$ & $0.96(0.81-1.14)$ & $0.98(0.84-1.13)$ \\
\hline Belgium & 52.1 & 44.3 & 39.1 & $1.29(1.19-1.40)$ & $1.13(1.03-1.23)$ & $1.10(0.96-1.25)$ & $1.17(1.04-1.32)$ \\
\hline Germany & 70.6 & 71.4 & 62.1 & $1.20(1.07-1.34)$ & $1.16(1.04-1.30)$ & $1.22(1.04-1.42)$ & $1.10(0.93-1.30)$ \\
\hline France & 79.7 & 81.5 & 81.0 & $0.98(0.91-1.06)$ & $0.93(0.86-1.01)$ & $0.89(0.79-1.01)$ & $0.99(0.88-1.10)$ \\
\hline Hungary & 73.2 & 73.1 & 74.8 & $0.97(0.89-1.06)$ & $0.87(0.80-0.95)$ & $0.82(0.72-0.94)$ & $0.92(0.82-1.03)$ \\
\hline Estonia & 69.0 & 70.0 & 67.2 & $0.98(0.85-1.13)$ & $0.91(0.79-1.05)$ & $0.82(0.65-1.03)$ & $0.97(0.81-1.18)$ \\
\hline Latvia & 47.3 & 45.3 & 46.8 & $0.97(0.85-1.10)$ & $0.92(0.80-1.04)$ & $1.00(0.81-1.23)$ & $0.87(0.74-1.03)$ \\
\hline Europe & 62.4 & 61.4 & 58.9 & $1.09(1.06-1.13)$ & $1.00(0.97-1.04)$ & $1.00(0.95-1.05)$ & $1.02(0.97-1.07)$ \\
\hline
\end{tabular}

Utilization of specialist services

$\begin{array}{lllllllll}\text { Norway } & 14.0 & 17.7 & 18.5 & 0.72(0.57-0.91) & 0.61(0.48-0.78) & 0.66(0.46-0.96) & 0.59(0.43-0.81) \\ \text { Ireland } & 25.6 & 22.5 & 27.1 & 0.84(0.70-1.02) & 0.59(0.49-0.72) & 0.57(0.43-0.76) & 0.62(0.47-0.80) \\ \text { Netherlands } & 17.9 & 18.1 & 17.2 & 1.05(0.91-1.21) & 0.86(0.73-1.00) & 0.90(0.72-1.13) & 0.88(0.71-1.09) \\ \text { Belgium } & 20.8 & 22.1 & 25.5 & 0.73(0.65-0.82) & 0.59(0.52-0.67) & 0.73(0.59-0.89) & 0.54(0.46-0.64) \\ \text { Germany } & 74.2 & 78.6 & 76.2 & 0.90(0.80-1.00) & 0.87(0.78-0.97) & 0.93(0.80-1.09) & 0.86(0.74-1.00) \\ \text { France } & 51.9 & 58.7 & 66.5 & 0.60(0.55-0.66) & 0.55(0.51-0.61) & 0.55(0.47-0.64) & 0.59(0.52-0.66) \\ \text { Hungary } & 47.4 & 54.0 & 59.6 & 0.72(0.65-0.80) & 0.58(0.52-0.65) & 0.60(0.51-0.72) & 0.61(0.53-0.70) \\ \text { Estonia } & 42.5 & 45.6 & 51.4 & 0.76(0.64-0.91) & 0.68(0.57-0.81) & 0.62(0.46-0.84) & 0.72(0.57-0.90) \\ \text { Latvia } & 26.0 & 29.0 & 39.3 & 0.51(0.44-0.60) & 0.47(0.40-0.55) & 0.51(0.38-0.68) & 0.46(0.38-0.55) \\ \text { Europe } & 33.1 & 36.4 & 40.2 & 0.74(0.71-0.77) & 0.65(0.62-0.67) & 0.70(0.65-0.75) & 0.66(0.62-0.69)\end{array}$

a Prevalence rate per 100 persons (men and women combined), age and gender standardized to the total survey population;

${ }^{\mathrm{b}}$ Relative index of inequality and $95 \%$ confidence interval adjusted for age and gender

' SAH = Self-assessed health

without exceptions. Relative inequalities were smaller in the Netherlands and Germany (RIIs around 0.86) and were very pronounced in Latvia ( $\mathrm{RII}=0.47$ ).

The pattern of utilisation of GP and specialist services for patients with chronic diseases, diabetes and hypertension was similar to that of the general population: lower and higher educated persons with chronic diseases were equally likely to use GP services in most countries (Table 4). Only in Belgium and Germany did lower educated patients report using GP services slightly more often. On the other hand, higher educated patients with chronic conditions used specialist services significantly more often than lower educated patients (RII $=0.87$ and lower), except in the Netherlands (RII $=0.92$; Table 4$)$. These inequalities tended to be larger in Norway, Belgium, France, Hungary and Latvia, and were somewhat smaller in the other countries.

\section{Discussion}

People with a lower education level used GP services slightly less often as those with a higher level of education in most countries (except for Belgium and Germany). At the same time, higher educated people used specialist care services significantly more often in all countries (except for the Netherlands). Educational inequalities in utilisation of specialist care among women were slightly larger than among men in some countries, although the general pattern of use was similar for both men and women. Inequalities in utilisation of specialist care were equally large in Eastern European and in Western European countries, except for Latvia where the level of inequalities was somewhat larger. Similarly large was the level of inequalities in utilisation of specialist care among patients with chronic diseases, diabetes, and hypertension.

The high percentage of non-response in some countries could have biased our results if both the educational level and the reported utilisation of services had been unequally distributed among respondents and nonrespondents. Although some studies reported that nonresponse is related to socioeconomic status [13-15], previous evaluations showed that the association between utilisation of services and socioeconomic status would 
Table 4 Relative index of inequality (RII) in utilisation of GP and specialist services among patients with chronic diseases; men and women combined

\begin{tabular}{|c|c|c|c|}
\hline Country & $\begin{array}{l}\text { Chronic diseases } \\
\text { RII }^{a}(95 \% \mathrm{CI})\end{array}$ & $\begin{array}{c}\text { Diabetes } \\
\text { RII }(95 \% \mathrm{Cl})\end{array}$ & $\begin{array}{c}\text { Hypertension } \\
\text { RII }(95 \% \mathrm{CI})\end{array}$ \\
\hline \multicolumn{4}{|c|}{ Utilization of GP services } \\
\hline Norway & $0.99(0.79-1.24)$ & $0.99(0.57-1.69)$ & $0.96(0.71-1.31)$ \\
\hline Netherlands & $0.92(0.78-1.08)$ & $0.71(0.47-1.07)$ & $0.97(0.77-1.23)$ \\
\hline Belgium & $1.15(1.00-1.31)$ & $1.27(0.86-1.88)$ & $1.19(0.98-1.44)$ \\
\hline Germany & $1.11(0.94-1.32)$ & $1.74(1.02-2.97)$ & $1.14(0.90-1.44)$ \\
\hline France & $1.03(0.89-1.19)$ & $0.98(0.66-1.46)$ & $1.03(0.86-1.24)$ \\
\hline Hungary & $0.91(0.78-1.06)$ & $0.93(0.69-1.24)$ & $0.90(0.74-1.10)$ \\
\hline Estonia & $0.99(0.81-1.22)$ & $1.10(0.61-1.98)$ & $1.00(0.75-1.33)$ \\
\hline Latvia & $0.97(0.75-1.25)$ & $0.71(0.31-1.67)$ & $1.04(0.75-1.44)$ \\
\hline Europe & $1.03(0.97-1.09)$ & $1.03(0.88-1.20)$ & $1.05(0.96-1.14)$ \\
\hline \multicolumn{4}{|c|}{ Utilization of specialist services } \\
\hline Norway & $0.55(0.36-0.84)$ & $0.62(0.25-1.57)$ & $0.50(0.28-0.90)$ \\
\hline Netherlands & $0.92(0.74-1.13)$ & $0.71(0.43-1.18)$ & $0.86(0.62-1.18)$ \\
\hline Belgium & $0.64(0.52-0.78)$ & $0.50(0.29-0.87)$ & $0.65(0.48-0.87)$ \\
\hline Germany & $0.87(0.74-1.02)$ & $0.83(0.52-1.34)$ & $0.87(0.69-1.09)$ \\
\hline France & $0.68(0.54-0.85)$ & $0.77(0.49-1.20)$ & $0.64(0.51-0.79)$ \\
\hline Hungary & $0.63(0.52-0.75)$ & $0.72(0.52-1.00)$ & $0.60(0.47-0.77)$ \\
\hline Estonia & $0.76(0.59-0.97)$ & $0.77(0.38-1.57)$ & $0.74(0.51-1.07)$ \\
\hline Latvia & $0.60(0.43-0.84)$ & $0.83(0.25-2.70)$ & $0.66(0.43-1.01)$ \\
\hline Europe & $0.71(0.66-0.77)$ & $0.72(0.59-0.86)$ & $0.69(0.62-0.77)$ \\
\hline
\end{tabular}

a Relative index of inequality (95\% confidence interval) adjusted for age, gender, and self-assessed health

not greatly change if non-respondents were included with respondents $[16,17]$. Nevertheless, in the present study we cannot exclude the possibility that an overrepresentation of sicker lower educated people in the non-response group may have led to some underestimation of the pro-rich inequalities in prevalence rates of utilisation reported here.

We used education as an indicator of socioeconomic position. Education allows the classification of individuals who do not work, prevents reverse causation, and facilitates international comparisons due to its relative ease of measurement. In addition, recent studies suggest that in some countries education has an independent effect and is more strongly related to the likelihood of health services utilisation than income and employment status $[18,19]$. On the other hand, educational level might not accurately indicate an older person's current socioeconomic position since it is acquired early in life and may inadequately reflect changes in socioeconomic position during adult life [20].

There were large differences between countries in the educational distribution. These differences reflect, in part, the real situation of educational attainment in different countries of Europe [21]. However, there is a possibility that the ISCED classification is not flexible enough to accommodate different national schemes. To cope with the differences in educational classification we used the RII, a measure that takes educational distribution into account $[11,12]$. Additionally, RII has the advantage that it can be applied in a comparable way to all countries provided that the educational classifications are strictly hierarchical.

The recall period for use of GP and specialist services was shorter in the Netherlands and Belgium than in the other countries. A longer recall period would have influenced the overall utilisation rates for the total population. It is, however, unlikely that it would have a differential effect on utilisation of services by different educational groups.

Self-assessed health was used in order to control for the health care needs of the population. Although the measure of self-assessed health is often used in health care research due to its wide availability and good comparability, it does not completely encompass the full spectrum of need. A better control for need would likely result in greater inequalities in specialist visits, while inequalities in GP visits might have also emerged in some countries.

Most European countries have achieved universal access to health care. However, the results of the present study show that universal access does not mean equal use. One might argue that differences in utilisation do not directly reflect inequalities in access to care. The decision to use health care services and the type of provider is, after all, a personal choice. Nevertheless, this personal choice is affected to a large extent by various enabling and predisposing factors. People from lower socioeconomic strata are likely to have fewer enabling factors and more barriers to use specialist care.

European countries have very different health care systems. For example, some countries operate with GP gate keeping (e.g. the UK, the Netherlands), others have more direct access to specialists and hospital care (France); some countries use only public insurance (Germany, the Netherlands), others only private or a combination of the two (Spain, Portugal); some countries use co-payments, others do not; etc. Regardless of the way the system is organised, we find a generalised pattern of differential access to primary and secondary care for people with different socioeconomic positions. Such a universal pattern indicates that patients with a lower socioeconomic position encounter barriers that are common in all countries, and thus lie beyond the national structure and organisation of the health care system.

Proper communication between the patient and health provider where the patient not only receives information about his disease, diagnostic procedures, and treatment, but also feels understood and helped is essential. Successful communication contributes to both patient outcomes $[22,23]$ and general satisfaction with services $[24,25]$. 
People with a lower socioeconomic position may better appreciate communication with the GP than with a specialist, as the former may be clearer in discussing the disease, be better at understanding and addressing the needs of the patient and, thus, be perceived as more trustworthy. On the other hand, patients with a higher socioeconomic position may trust a "higher specialised" provider and request contact with the specialist, or seek this contact directly thus avoiding the primary care provider. It is suggested that patients with lower education, lower income and ethnic background express more preference to see a GP for their initial care than better educated, higher income white patients [26], although research in this area is very limited and sometimes contradictory [27]. Higher educated patients that chose a GP for their initial contact (either as personal choice or due to organisational enforcement, as in countries with a gate keeping system) are usually better able to articulate their needs for the specialist and have greater assertiveness regarding being referred to one [28,29], leading to a higher number of referrals.

One may suggest that a simple substitution of care occurs i.e. equal quality care for the same problem, which is performed by one type of provider instead of another without any consequences for the health outcomes of the patient. Our data, however, indicate that lower-educated people use GP services slightly less often compared to higher-educated people in most European countries, while inequalities in the use of specialists are large. A better control for need of care may even reveal pro-rich inequalities in the use of GP services. Thus, we do not find evidence for the substitution of care. Others also showed that the likelihood to consult a specialist increases given a consultation with the general practitioner [2].

Another common feature of the health care system is its enormous complexity: whichever type of organisation exists in a country it is never easily understood, particularly by those with a lower socioeconomic position. This complexity is often coupled with constant changes in the way the system operates that may disorient even welleducated patients. Since primary care (GP practices) is the easiest, most accessible and least changeable type of care, people with a lower socioeconomic position may not feel inclined to go further up the hierarchy of the health care organization, in order to avoid this confusing complexity.

Within the generalised pattern of differential utilisation of different types of services, there remain some variations that indicate that national health care systems may play an additional role in (dis-)motivating patients to use particular types of care. For example, compared to other countries, we observed larger inequalities in the use of specialist care in Latvia and smaller inequalities in the Netherlands. Similar differences were also observed in studies on income inequalities in utilisation of care [30]. It is plausible that these variations in the magnitude of inequalities are driven by differences in health system characteristics, such as sources of finance and service delivery practices. For example, in the Netherlands there is a stronger GP gate keeping system compared to other countries included in this study. A strong GP gate keeping system may allow a better control of the patient flow to specialists that is in accordance with clinical guidelines (and needs of the patients), thus leaving less room for inequalities in the utilisation of specialist care to occur compared to a more free-way system [31].

We hypothesized that inequalities in access to care in East European countries would be larger than in the West European countries due to disruption of the social protection and health care systems that occurred during the 1990s in many former Soviet countries. Our data do indicate larger inequalities in use of specialist care in Latvia. Compared to the neighbouring countries, Latvia has implemented a system with larger co-payment mechanisms for public health services. Thus, the financial barriers met by the population for the use of health services might have resulted in much lower utilisation rates and the highest level of inequalities observed in the present study. Also in Hungary, in addition to large inequalities in utilisation of specialist care, there were significant pro-rich inequalities in the use of GP services, indicating gross general inequalities in utilisation of health services. Our findings are supported by studies reporting larger inequalities in mortality amenable to medical care found in East European countries compared to West European countries [32-34]. However, in Estonia the magnitude of inequalities in utilisation of care was similar to that of West European countries, which indicates that the problem is limited to particular countries and can not be generalised to all East European countries.

The present study paid particular attention to people with chronic diseases. The results show large inequalities in utilisation of specialist services in this vulnerable group. Hampered access to specialist care might have a more severe impact on the health status of patients with high need, such as the chronically diseased, compared to the general population. Thus, there is an urgent need to investigate and remove barriers to the use of specialist care among patients with chronic diseases.

\section{Conclusions}

In summary, large inequalities were observed in the utilisation of specialist care that are not compensated for by the use of GP services. Of particular concern is the presence of inequalities among patients with a high need for specialist care, such as those with chronic diseases, which 
raises important issues regarding the access to care among vulnerable subgroups.

\section{Acknowledgements and funding}

This investigation has been funded by the Health \& Consumer Protection Directorate-General of the European Union and was carried out as a part of the Eurothine project (Grant number 2003125). The study sponsors have not influenced in any form study design, collection, analysis, and interpretation of data, writing of the paper, and decision to submit it for publication. We also thank the following members of the European Union Working Group on Socioeconomic Inequalities in Health and the 'Eurothine' project who provided the National Survey Data:

Scientific Institute of Public Health, Brussels - H. van Oyen, S. Demarest; National Institute for Health Development, Department of Epidemiology and Biostatistics, Tallinn, Estonia - M. Tekkel;

Institut National de la Statistique et des Études Économiques, Paris - G. Desplanques; Research and Information Institute for Health Economics, Paris F. Jusot;

Center for Social Policy Research, University of Bremen, Bremen, Germany U. Helmert;

Demographic Research Institute, Hungarian Central Statistical Office, Budapest, Hungary - K. Kovacs;

Hungarian National Center of Epidemiology, Budapest, Hungary - F. Marton; Economic and Social Research Institute,Dublin - R. Layte

Faculty of Public Health, Riga Stradins University, Riga, Latvia - A. Villerusa; Centraal Bureau voor de Statistiek, Voorburg, the Netherlands - J.J.M. Geurts; Research Program Care, Health and Welfare, Oslo University College, Oslo E. Dahl; Division of Epidemiology, Norwegian Institute of Public Health, Oslo B.H. Strand

\section{Author details}

'Department of Public Health, Erasmus Medical Centre Rotterdam, Erasmus University, The Netherlands. ${ }^{2}$ Department of Public Health, Academic Medical Centre (AMC), University of Amsterdam, The Netherlands. ${ }^{3}$ Institute of Health Economics and Health Care Management, Helmholtz Zentrum München - German Research Center for Environmental Health, Germany.

\section{Authors' contributions}

IS designed the study, performed the statistical analysis and wrote the main draft of the manuscript. AK supervised the study and provided comments to all drafts of the manuscript. AM contributed to study design and provided comments to drafts of the paper. JM conceived the study and contributed to draft the manuscript. All authors read and approved the final manuscript.

\section{Competing interests}

The authors declare that they have no competing interests.

Received: 12 January 2011 Accepted: 31 October 2011 Published: 31 October 2011

\section{References}

1. van Doorslaer E, Masseria C, Koolman X, et al: Inequalities in access to medical care by income in developed countries. Cmaj 2006, 174(2):177-83.

2. Van der Meer JB: Equal care, equal cure? Socioeconomic differences in the use of health services and the course of health problems [thesis] Public Health Erasmus University Rotterdam: Rotterdam; 1998.

3. van Doorslaer $E$, Jones $A M$ : Income-related inequality in health and health care in the European Union. Health Econ 2004, 13(7):605-8.

4. Lorant $\mathrm{V}$, Boland $\mathrm{B}$, Humblet $\mathrm{P}$, et al: Equity in prevention and health care. J Epidemiol Community Health 2002, 56(7):510-6.

5. Goddard M, Smith P: Equity of access to health care services: theory and evidence from the UK. Soc Sci Med 2001, 53(9):1149-62.

6. Paterson I, Judge K, eds: Equality of access to healthcare. Reducing inequalities in health: A European perspective.Edited by: Mackenbach J Bakker M. Routledge: London and New York; 2002:

7. van Doorslaer $E$, Wagstaff $A$, van der Burg $H$, et al: Equity in the delivery of health care in Europe and the US. J Health Econ 2000, 19(5):553-83.
8. Walters S, Suhrcke M: Socioeconomic inequalities in health and health care access in central and eastern Europe and the CIS: a review of the recent literature. WHO European Office for Investment for Health and Development 2005

9. McKee M, Shkolnikov V: Understanding the toll of premature death among men in eastern Europe. Bmj 2001, 323(7320):1051-5.

10. Balabanova D, McKee M, Pomerleau J, et al: Health service utilization in the former soviet union: evidence from eight countries. Health Serv Res 2004, 39(6 Pt 2):1927-50.

11. Kunst $A E$, Mackenbach JP: Measuring socio-economic inequalities in health. World Health Organization: Copenhagen; 2000, p54

12. Kunst $A, B o s$ V, Mackenbach J: Guidelines for monitoring health inequalities in the European Union. Erasmus MC, Department of Public health: Rotterdam; 2001.

13. Martikainen $P$, Laaksonen $M$, Piha $K$, et al: Does survey non-response bias the association between occupational social class and health? Scand J Public Health 2007, 35(2):212-5.

14. Drivsholm T, Eplov LF, Davidsen M, et al: Representativeness in population-based studies: a detailed description of non-response in a Danish cohort study. Scand J Public Health 2006, 34(6):623-31.

15. Boshuizen HC, Viet AL, Picavet HS, et al: Non-response in a survey of cardiovascular risk factors in the Dutch population: determinants and resulting biases. Public Health 2006, 120(4):297-308.

16. Reijneveld SA, Stronks $K$ : The impact of response bias on estimates of health care utilization in a metropolitan area: the use of administrative data. Int J Epidemiol 1999, 28(6):1134-40

17. Reijneveld SA, Stronks K: The validity of self-reported use of health care across socioeconomic strata: a comparison of survey and registration data. Int J Epidemiol 2001, 30(6):1407-141.

18. Habicht J, Kunst AE: Social inequalities in health care services utilisation after eight years of health care reforms: a cross-sectional study of Estonia, 1999. Soc Sci Med 2005, 60(4):777-87.

19. Halldorsson $M$, Kunst $A E$, Kohler $L$, et al: Socioeconomic differences in children's use of physician services in the Nordic countries. J Epidemiol Community Health 2002, 56(3):200-4.

20. Huisman $M$, Kunst $A E$, Bopp $M$, et al: Educational inequalities in cause-specific mortality in middle-aged and older men and women in eight western European populations. Lancet 2005, 365(9458):493-500.

21. Rodríguez-Pose A, Tselios V: Mapping the european regional educational distribution: educational attainment and inequality. Instituto Madrileño de Estudios Avanzados (IMDEA) Ciencias Sociales: Madrid; 2007.

22. Di Blasi Z, Harkness E, Ernst $E$, et al: Influence of context effects on health outcomes: a systematic review. Lancet 2001, 357(9258):757-62

23. Meryn S: Improving doctor-patient communication. Not an option, but a necessity. Bmj 1998, 316(7149):1922.

24. Butler CC, Rollnick S, Pill R, et al: Understanding the culture of prescribing: qualitative study of general practitioners' and patients' perceptions of antibiotics for sore throats. Bmj 1998, 317(7159):637-42.

25. Saha S, Arbelaez JJ, and Cooper LA: Patient-physician relationships and racial disparities in the quality of health care. Am J Public Health 2003, 93(10):1713-9.

26. Wong MD, Asch SM, Andersen RM, et al: Racial and ethnic differences in patients' preferences for initial care by specialists. Am J Med 2004 116(9):613-20

27. Groholt $E$, Stigum $H$, Nordhagen $R$, et al: Health service utilization in the Nordic countries in 1996: Influence of socio-economic factors among children with and without chronic health conditions. Eur J Public Health 2003, 13(1):30-7.

28. Little $\mathrm{P}$, Dorward $M$, Warner $G$, et al: Importance of patient pressure and perceived pressure and perceived medical need for investigations, referral, and prescribing in primary care: nested observational study. Bmj 2004, 328(7437):444.

29. Morgan $M$, Jenkins $L$, and Ridsdale $L$ : Patient pressure for referral for headache: a qualitative study of GPs' referral behaviour. Br J Gen Pract 2007, 57(534):29-35.

30. Wagstaff $A$, van Doorslaer $E$, van der Burg $H$, et al: Equity in the finance of health care: some further international comparisons. $J$ Health Econ 1999 18(3):263-90 
31. Forrest $C B$, Nutting $P A$, von Schrader $S$, et al: Primary care physician specialty referral decision making: patient, physician, and health care system determinants. Med Decis Making 2006, 26(1):76-85.

32. Nolte $E$, Scholz R, McKee M: Progress in health care, progress in health? Patterns of amenable mortality in central and eastern Europe before and after political transition. Demographic research 2004, 2(6).

33. Nolte E, Scholz R, Shkolnikov V, et al: The contribution of medical care to changing life expectancy in Germany and Poland. Soc Sci Med 2002, 55(11):1905-21.

34. Stirbu I, Kunst A, Bopp M, et al: Educational inequalities in avoidable mortality in Europe. Eurothine Final Report Department of Public Health, Erasmus Medical Center: Rotterdam; 2007.

\section{Pre-publication history}

The pre-publication history for this paper can be accessed here: http://www.biomedcentral.com/1472-6963/11/288/prepub

doi:10.1186/1472-6963-11-288

Cite this article as: Stirbu et al:. Inequalities in utilisation of general practitioner and specialist services in 9 European countries. BMC Health Services Research 2011 11:288.

\section{Submit your next manuscript to BioMed Central} and take full advantage of:

- Convenient online submission

- Thorough peer review

- No space constraints or color figure charges

- Immediate publication on acceptance

- Inclusion in PubMed, CAS, Scopus and Google Scholar

- Research which is freely available for redistribution

Submit your manuscript at www.biomedcentral.com/submit 